\title{
Pressupostos políticos e teóricos do curso de formação "melhor gestão, melhor ensino" da SEE/SP (2013-2017)
}

\author{
Political and theoretical assumptions on the \\ training course 'better management, better teaching', of the \\ São Paulo State Department of Education (2013-2017) \\ Supuestos políticos y teóricos del curso de formación "mejor gestión, mejor \\ enseñanza" de la Secretaría de Educación del Estado de São Paulo (2013-2017) \\ LUIS FERNANDO FERREIRA PINTO \\ https://orcid.org/0000-0002-3783-7627 \\ Universidade Estadual de Campinas \\ Faculdade de Educação \\ São Paulo, SP, Brasil \\ REGIS HENRIQUE DOS REIS SILVA \\ https://orcid.org/0000-0001-6392-0697 \\ Universidade Estadual de Campinas \\ Faculdade de Educação \\ São Paulo, SP, Brasil
}

\begin{abstract}
Resumen: Este artigo objetiva identificar e discutir os pressupostos políticos e teóricos do curso de formação de diretores "Melhor Gestão, Melhor Ensino" da SEE/SP, oferecido entre os anos de 2013 e 2017. Metodologicamente, os pressupostos da Pedagogia Histórico- Crítica guiaram uma abordagem histórica do projeto de formação do diretor a partir da análise de decretos e leis em vigor entre 1996 e 2016. Os resultados consideram o contexto histórico, político e teórico em que o curso foi proposto e permitem perceber a influência da mundialização da cultura do capital e da "Pedagogia do Aprender a Aprender".
\end{abstract}

Palabras clave: diretor escolar, gestão escolar, neoliberalismo.

Resumo: This article aims to identify and discuss the political and theoretical assumptions of the training course for directors "Better Management, Better Teaching" (MGME), offered by the São Paulo State Department of Education (SEE/SP) from 1996 to 2016. Methodologically, the assumptions of critical historical pedagogy guided a historical approach to the training project for directors based on the analysis of decrees and laws in effect between 1996 and 2016. The results consider the historical, political, and theoretical context in which the course was proposed and allow to perceive the influence of globalization of the capital culture and the "Learn to Learn Pedagogy".

Palavras-chave: Pschool principal, school management, neoliberalism. 
Abstract: Este articulo tiene el objetivo de identificar y discutir los supuestos politicos y teóricos del curso de formación de directores "Mejor Gestión, Mejor Enseñanza" de la Secretaría de Educación del Estado de São Paulo (SEE/SP) ofrecido entre 2013 y 2017. Metodológicamente, los supuestos de la pedagogía histórica crítica orientaron un abordaje bistórico del proyecto de formación del director basado en el análisis de decretos y leyes vigentes entre 1996 y 2016. Los resultados consideran el contexto histórico, político y teórico en el que se propuso el curso y permiten percibir la influencia de la globalización de la cultura del capital y de la "Pedagogía del Aprender a Aprender".

Keywords: director de escuela, gestión escolar, neoliberalismo.

\section{INTRODUÇÃO}

O presente texto discorre sobre o processo de formação do diretor escolar conforme proposto pela Secretaria de Educação do Estado de São Paulo (SEE/SP). Para tanto, analisamos o curso de formação "Melhor Gestão, Melhor Ensino" (MGME), oferecido pela Escola de Formação e Aperfeiçoamento de Professores Paulo Renato de Souza (EFAP) entre os anos de 2013 e 2017. Tratase do primeiro curso de formação para diretor oferecido via Educação à Distância (EaD) pela SEE/SP.

Nosso objetivo foi identificar e discutir os pressupostos políticos e teóricos desse curso e compreender o projeto de formação do diretor no âmbito da mundialização do capital, considerando as políticas públicas educacionais brasileiras das últimas décadas, sob a luz da Pedagogia Histórico-Crítica (PHC).

As ações políticas para a formação do educador paulista intensificamse a partir da criação do programa "São Paulo Faz Escola", responsável pela implantação do Currículo Oficial do Estado de São Paulo.

No decorrer da implantação do Currículo Paulista, foi criada em 2001 a Rede do Saber, que se tornou uma das maiores redes públicas de videoconferências com finalidade pedagógica da América Latina e tem, como princípio, promover a formação continuada e o desenvolvimento profissional. A partir de 2009, essa instituição passou a integrar a EFAP, organização que oferece cursos de formação continuada aos 270 mil funcionários da SEE/SP. Por isso, a Rede do Saber possui uma estrutura física interligada por todo o Estado e conta com 182 salas em 91 polos, que funcionam em todas as diretorias de ensino da SEE/SP.

A partir de 2008, mais de 5 mil escolas passaram a se conectar às videoconferências da SEE/SP. Essas videoconferências colaboram para a capacitação docente, auxiliando no processo de formação contínua dos educadores, bem como apoiam as atividades de gestão e ampliam ações. Vinculase à Rede do Saber o Centro de Referência em Educação Mário Covas (CRE), como acervo de textos e legislação educacional a ser consultado pelos educadores. 
Sete anos após a criação da Rede do Saber, a SEE/SP divulgou a Proposta Curricular do Estado de São Paulo, que entrou em vigor em 2008 por meio da Resolução SE n. 76, de 7 de novembro de 2008. Implantada no governo José Serra, essa proposta teve como principais autores Maria Helena Guimarães de Castro, Guiomar Namo de Mello, Maria Inês Fini, Lino de Macedo, Zuleika de Felice Murrie e Paulo Renato de Souza. No ano de 2008, os gestores também receberam o Caderno do Gestor, material cujo propósito era subsidiá-los na implantação da Proposta Curricular de São Paulo que fazia parte do programa "São Paulo Faz Escola".

Também vinculado ao programa estava o curso de formação MGME, objeto de análise deste artigo. Esse curso voltava-se para os diretores e foi dividido em três módulos: no primeiro, o foco era pensar a sala de aula; no segundo, as reflexões tinham como objeto a gestão de pessoas; finalmente, no terceiro, abordavam-se os resultados da aprendizagem.

O MGME era o mais extenso dentre os cursos direcionados aos diretores escolares oferecidos pela SEE/SP e sua última edição ocorreu no ano de 2017. $\mathrm{O}$ fato de ele consistir em uma referência para os gestores da rede motivou-nos a tomá-lo como objeto de análise, dedicando-nos, inicialmente, ao exame das referências e da perspectiva histórica subjacentes a sua constituição.

\section{PRESSUPOSTOS POLÍTICOS DO CURSO "MELHOR GESTÃO, MELHOR ENSINO"}

O curso MGME era ministrado pela EFAP, criada oficialmente por meio do decreto n. 54.297, de 5 de maio de 2009.

A Resolução SE n. 56, de 14 de outubro de 2016, discorre sobre o perfil, as competências e habilidades requeridas aos Diretores de Escola, bem como sobre as referências bibliográficas e a legislação que fundamentam e orientam a organização de concursos públicos e processos seletivos do referido cargo da SEE/SP. Segundo essa resolução, o perfil do diretor escolar deve contemplar:

\footnotetext{
Gestão democrática e participativa, planejamento estratégico, foco em qualidade e resultados, gestão pedagógica, gestão de processos administrativos, gestão de pessoas e equipes, um perfil como dirigente e coordenador do processo educativo [...] tem como objetivo a melhoria do processo educativo e do desempenho da escola, cabe ao diretor mediante processos de pesquisa e formação continuada em serviço, assegurar o desenvolvimento de competências e habilidades dos profissionais que trabalham sob a sua coordenação, nas diversas dimensões de gestão escolar participativa, pedagógica, de pessoas, de recursos físicos, financeiros e de resultados. (SÃO PAULO, 2016a).
} 
A carreira de diretor passou a contar com estágio probatório e avaliação periódica de desempenho individual, de acordo com a Lei Complementar n. 2.156 de 2015. Aos aprovados no concurso para diretor da SEE/SP foi solicitado que frequentassem cursos de formação continuada oferecidos pela EFAP, conforme estabelece o artigo $2^{\circ}$ da Lei Complementar n. 1.207, de 5 de julho de 2013. Vale destacar que os cursos específicos para ingressantes em cargos do quadro do magistério fazem parte do estágio probatório.

Sintetizamos, no quadro abaixo, as principais resoluções e decretos que regeram a vida institucional e indicam os papeis a serem desempenhados pelos diretores de escolas da Secretaria Estadual de Educação de São Paulo no período de 1996 a 2016.

\section{Quadro 1.1 - Legislação analisada no período de 1996 a 2016}

\begin{tabular}{|c|c|}
\hline 1996 & $\begin{array}{l}\text { Resolução SE n. 27, de } 29 \text { de março de } 1996 . \\
\text { Dispõe sobre o Sistema de Avaliação de Rendimento Escolar. [Articulado com o Sistema Nacional de Educação } \\
\text { Básica (SAEB/MEC)]. } \\
\text { Decreto n. 40.673, de } 16 \text { de fevereiro de } 1996 . \\
\text { Institui o Programa de Ação de Parceria Educacional Estado/Município para atendimento ao ensino fundamental em } \\
\text { São Paulo. [Descentralização da Gestão Educacional Estado/Município]. }\end{array}$ \\
\hline 1997 & $\begin{array}{l}\text { Deliberação CEE n. } 9 \text { de 1997, aprovada em } 30 \text { de julho de } 1997 . \\
\text { Institui, no Sistema de Ensino do Estado de São Paulo, a progressão continuada no ensino fundamental [números } \\
\text { quantitativos / aceleração da aprendizagem] } \\
\text { Diretrizes para elaboração de Regimento das Escolas do Estado de São Paulo. } \\
\text { Lei Complementar n. 836, de } 30 \text { de dezembro de } 1997 . \\
\text { Institui Plano de Carreira, Vencimentos e Salários para os integrantes do Quadro do Magistério. [Suporte pedagógico } \\
\text { aos gestores.] }\end{array}$ \\
\hline 2005 & $\begin{array}{l}\text { Resolução SE n. 24, de } 5 \text { de abril de } 2005 . \\
\text { Dispõe sobre Escola em Parceria. }\end{array}$ \\
\hline 2007 & $\begin{array}{l}\text { Lançamento do Caderno do Programa de Qualidade da Escola. (Subsídios ao Gestor para a busca de resultados). } \\
\text { Lei Complementar n. } 1.018 \text {, de } 15 \text { de outubro de } 2007 \text {. } \\
\text { Institui gratificação ao professor coordenador e vice-diretor de escola. }\end{array}$ \\
\hline 2008 & $\begin{array}{l}\text { Decreto n. } 52.630 \text {, de } 16 \text { de janeiro de } 2008 . \\
\text { Estabelece ao diretor de escola o dever de atender os critérios definidos por estudos da SEE/SP. [Caderno do Gestor } \\
\text { / Orientações ao Gestor Escolar]. } \\
\text { Resolução SE n. } 40 \text {, de } 13 \text { de maio de } 2008 \text {. } \\
\text { Dispõe sobre estudos de recuperação na rede estadual de ensino. } \\
\text { Lei Complementar n. } 1.078 \text {, de } 17 \text { de dezembro de } 2008 . \\
\text { Institui o sistema de Bonificação por Resultados. }\end{array}$ \\
\hline 2009 & $\begin{array}{l}\text { es de referência para a avaliação SARESP: documento básico. } \\
\text { tações sobre as matrizes de referência SARESP]. }\end{array}$ \\
\hline
\end{tabular}




\section{Quadro 1.1 - Legislação analisada no período de 1996 a 2016}

\begin{tabular}{|l|l|}
\hline 2011 & $\begin{array}{l}\text { Decreto n. 57.571, de } 2 \text { de dezembro de } 2011 . \\
\text { Institui, junto à Secretaria de Educação, o Programa Educação-Compromisso de São Paulo. }\end{array}$ \\
\hline 2013 & $\begin{array}{l}\text { Resolução n. 22, de } 18 \text { de abril de 2013. } \\
\text { Prevê o desenvolvimento de ações que visam a melhoria da educação básica paulista. }\end{array}$ \\
\hline 2015 & $\begin{array}{l}\text { Lei Complementar n. 1.256, de } 6 \text { de janeiro de 2015. } \\
\text { Dispõe sobre Estágio Probatório e institui Avaliação Periódica de Desempenho Individual para os ocupantes do cargo } \\
\text { de Diretor de Escola. }\end{array}$ \\
\hline 2016 & $\begin{array}{l}\text { Resolução n. 56, de 14 de outubro de 2016. } \\
\text { Dispõe sobre perfil, competências e habilidades requeridos dos Diretores de Escola da rede estadual de ensino. }\end{array}$ \\
\hline
\end{tabular}

Fonte: SÃO PAULO. Diário Oficial do Estado de São Paulo (DOE-SP).

A Lei Complementar que regulamenta o cargo de diretor escolar na rede estadual de São Paulo é a de n. 836, de 30 de dezembro de 1997. Baseando-se nela, um dos pré-requisitos para ocupar o referido cargo foi ter no mínimo oito anos de efetivo exercício de magistério. Para o vice-diretor da Escola da Família, há a Resolução SE n. 32, de 26 de maio de 2011, para escolas da periferia de grandes cidades como Campinas, que torna a escola um espaço de "lazer comunitário" nos finais de semana.

Notemos também que através dos decretos e leis, a formação do educador e do gestor será realizada pela EFAP, conforme estabelecido pela Resolução SE n. 22, de 18 de abril de 2013:

Artigo $1^{\circ}$ - Fica instituído, no âmbito da Secretaria da Educação, o Programa "Melhor Gestão, Melhor Ensino", destinado aos profissionais de educação, das classes de gestores e docentes, com a finalidade de fortalecer-lhes as competências requeridas para o desempenho de suas respectivas funções, na rede estadual de ensino, em especial nos anos finais do ensino fundamental, mediante ações de formação continuada.

$[\ldots]$

Artigo $6^{\circ}$ - A EFAP - Escola de Formação e Aperfeiçoamento dos Professores do Estado de São Paulo, Paulo Renato Costa Souza, editará, caso necessário, orientações complementares para o cumprimento do disposto na presente resolução.

Artigo $7^{\circ}$ - Esta resolução entra em vigor na data de sua publicação. (SÃO PAULO, 2013).

O curso em questão, vinculado ao Decreto n. 57.571, de 2 de dezembro de 2011, entrou em vigor no ano de 2013, por meio da Resolução n. 22, de 18 de abril de 2013, com o propósito de "prever o desenvolvimento de ações que visam à melhoria da educação básica paulista” (SÃO PAULO, 2013, p. 73). Tanto a primeira edição do curso (2013), quanto as posteriores $(2014,2017)$ possuem a mesma formatação. A carga horária compunha um total de 80 horas, divididas em 24 horas de encontros presenciais nas diretorias de ensino, 8 horas de 
videoconferências e 8 horas de seminários descentralizados; o restante do tempo era distribuído entre observação das aulas dos professores, reflexões, atividades desenvolvidas no Ambiente Virtual de Aprendizagem (AVA) da EFAP e a elaboração de um plano de ação do diretor como atividade final, após a realização de todas as atividades.

As atividades a distância estavam disponíveis em um site específico, ocorriam ao final de cada módulo e eram contabilizadas na participação do curso. Elas consistiam em fóruns e em questões objetivas e discursivas sobre os conteúdos de cada módulo e eram validadas por um professor tutor que avaliava as atividades e lhes atribuía um conceito. Após a validação dos conceitos, o cursista recebia um certificado de participação a ser utilizado em sua evolução funcional. Cabe ressaltar que, na SEE/SP, o gestor que deseja obter evolução funcional pela via não acadêmica precisa realizar os cursos oferecidos pela EFAP.

O enfoque do curso é a elaboração de estratégias pedagógicas. Para tanto, o educador é instigado a compreender a importância da formação regional para professores e a elaboração de planos de ação para as escolas por meio de socialização de atividades. O público-alvo, além do diretor escolar, também contemplou vice-diretores e professores coordenadores. Para a edição de 2017, foram oferecidas "13.116 vagas, a serem preenchidas, por adesão e por ordem de inscrição” (SÃO PAULO, 2017, p. 4). Em relação aos anos de 2013 e 2014, não foi apresentada nos regulamentos a quantidade possível de inscrições.

Além disso, cabe uma reflexão política acerca da maneira como o governo se reconfigura e o Estado era combatido para não mais gestar. Nesse sentido, apoiamo-nos em Dardot e Laval, que observam que:

O Estado neoliberal não é, portanto, um instrumento que se possa utilizar indiferentemente para finalidades contrárias. Enquanto Estado estrategista codecididor dos investimentos e das normas, ele é uma peça da máquina que se deve combater. (DARDOT; LAVAL, 2016, p. 31).

Notamos que essas ações da SEE/SP seguem a lógica de implementação de uma política neoliberal de caráter centralizador e verticalizado, afinal o neoliberalismo "define-se como o conjunto dos discursos, práticas e dispositivos que determinam um novo modo de governo dos homens segundo o princípio universal da concorrência" (DARDOT, LAVAL, 2016, p. 17), ou seja, essas políticas que foram implantadas definem o indivíduo como sua própria empresa, que deve saber gerir o lucro de qualquer forma no processo de mundialização do capital. 


\section{PRESSUPOSTOS TEÓRICOS DO CURSO "MELHOR GESTÃO, MELHOR ENSINO”}

A análise dos pressupostos teóricos que embasam o curso em questão permite abordar o modo como se deu, no estado de São Paulo, o processo de mundialização do capital e investigar os efeitos das políticas educacionais hegemônicas das últimas décadas. Chama-se atenção para o fato de que o curso MGME apresenta uma diferença significativa em relação a momentos históricos anteriores graças a sua amplitude, pois as tecnologias das telecomunicações permitem a participação via internet dos docentes, que podem realizar as atividades no momento em que for mais conveniente, em um modelo de EaD. Percebe-se a existência de uma espécie de "formação em massa", já que todos os educadores da SEE/SP, podem conectar-se ao conteúdo dos cursos através de teleconferência ou do acesso a endereços eletrônicos.

É notável, na leitura do MGME, que um dos principais assuntos contemplados é a gestão de pessoas. Logo na introdução do curso, enfatiza-se que as leituras, reflexões e atividades a serem desenvolvidas terão como foco a aprendizagem de todos os profissionais da escola e a integração deles para o cumprimento de uma meta comum: a promoção da aprendizagem dos alunos. As temáticas pedagógicas contempladas no curso estão divididas em módulos. Abordemos, pois, o modo como são dispostos os conteúdos.

Num primeiro módulo, inicialmente, o material apresenta tentativas de explicar a escola no passado, tendo como centro a figura do professor, ou seja, explicações que elucidam o foco do conhecimento no professor. Para tanto, abordam-se as mudanças nas concepções educacionais, com ênfase na aprendizagem do aluno e no estímulo ao desenvolvimento cognitivo. A temática, desenvolvida no módulo 1 estabelece, pois, o registro do processo de aprendizagem e o mapeamento da sala, para que o gestor saiba, segundo a EFAP, organizar o processo de aprendizagem e redefinir caminhos. O segundo módulo inicia-se fornecendo subsídios para que o educador tenha domínio sobre o perfil de cada função na escola, segundo o que regem as resoluções, decretos e leis. Após a apropriação desse conteúdo, cabe ao gestor não só saber identificar os conflitos na escola, mas também resolvê-los. Além disso, a definição das parcerias também cabe ao gestor, que precisa articular a escola, a diretoria de ensino e a SEE/SP com o objetivo de regular e controlar os sujeitos, suas relações e processos.

Apropriar-se dos caminhos para o alcance de melhores resultados é uma sugestão recorrente do curso. Por isso, são discutidas ações que podem colaborar para melhorar os resultados, sempre com foco na escola, tornando o ambiente um local organizado. Além disso, cabe ao diretor escolar ser um assíduo participante 
dos cursos de formação continuada disponibilizados pela EFAP e articular, em sua rotina, o Plano de Melhoria Educação Compromisso de São Paulo (20112030), as diretrizes e o Plano Estadual de Educação, promovendo uma constante "gestão de melhorias".

Segundo o MGME, cabe ao gestor romper com velhos modelos e responder pelo envolvimento de toda a comunidade. $\mathrm{Na}$ condição de líder do processo, deve estimular lideranças intermediárias para o alcance de resultados e estabelecer relações entre as dimensões técnicas e políticas dos sujeitos dentro da escola.

Dando prosseguimento à abordagem do perfil do diretor escolar, o Módulo 2 passa a discorrer sobre mérito, alegando-se que o gestor precisa engajarse na busca do mérito e de uma proposta de qualidade. Para tanto, deve embasarse nos princípios da gestão de melhoria e atentar sempre para conceitos como efetividade, relevância, eficácia, eficiência e qualidade. Parece-nos, pois, que existe a expectativa de que um gestor aja com extremo profissionalismo e envolva-se na construção coletiva de si e dos demais educadores e educandos, segundo o que se espera de uma gestão democrática.

Assim, o curso dá ênfase ao profissionalismo técnico-instrumental, centrado na ideia de competências isoladas. Por isso, discorre sobre a relevância de uma "gestão por competências", estratégia que é concebida como promissora porque possibilita integrar as diversas dimensões que compõem um campo profissional. Segundo as indicações do curso, uma gestão por competências facilita que a escola atinja objetivos institucionais, pois sua base é o desenvolvimento de competências denominadas Conhecimento, Habilidade e Atitude (CHA).

A sigla CHA dialoga com a ideia de um gestor que promove a melhoria progressiva valendo-se dos elementos Conhecimento, Habilidade e Atitude, que concebe ética como dever, conhecimento como saber, estética como prazer e técnica como ser. As competências do CHA levam em consideração as competências acadêmicas, pessoais e profissionais, pois são incorporadas às relações que estabelecemos. A reconfiguração das competências técnicas funciona como ponto de partida para o trabalho educativo, dando-lhe uma nova roupagem.

Também é atribuído ao gestor o papel de colaborar para a criação de contextos que permitam que os professores articulem teoria e prática, seja através de afazeres profissionais, seja por meio de espaços de formação. Frases como "nós somos o sistema" e "todos devem ser incluídos no sistema", alusão ao processo de inserção social, são elencadas ao longo de todo o curso, dando ênfase à ideia de que, na escola, todos os sujeitos são partes constitutivas de uma estrutura. 
As atividades propostas são permeadas por perguntas dirigidas aos gestores, as quais parecem ter objetivo de promover uma reflexão "a-histórica", já que estão atreladas à ideia de que é preciso construir uma escola que "facilite" a aprendizagem, relegando a segundo plano o modelo produzido de conhecimento característico da escola do passado.

No Módulo 3, abordam-se as avaliações interna e externa e as políticas de resultados, sugerindo-se atividades relativas às avaliações e aos resultados do SARESP. Um dos focos do módulo em questão é defender a importância da observação do que se reproduz em sala de aula, já estabelecida no Caderno do Gestor em 2008 aos diretores, como materialização da implantação da Proposta Curricular de São Paulo. Encontramos no Caderno do Gestor o mesmo perfil de liderança e monitoramento defendido no curso MGME de 2013 a 2017.

Em ambos, são feitos constantes questionamentos sobre o diálogo entre o gestor e o professor, sugerindo-se que os docentes são culpados pelo fracasso da reprovação. Tais diálogos, por sua vez, pressupõem uma escuta atenta por parte do gestor, a quem cabe acolher as concepções e perspectivas desse professor frente aos alunos, ao currículo e à própria gestão.

Em consonância com muitas das ideias que embasam tais propostas, boa parte da literatura disponibilizada nesse módulo compartilha da imagem do professor como um sujeito que possui uma formação insuficiente, que lhe impõe restrições quando se trata de facilitar a aprendizagem. Autores como Damis (2010) e Mazotti (2017) argumentam que a arquitetura das aulas deve ser modificada, havendo, pois, um fracasso que o professor não assume, pois limita-se a culpar o aluno pela falta de êxito do processo de ensino-aprendizagem.

Ao final de cada atividade do Módulo 3, os educadores são convidados a socializar vivências sobre observação de sala de aula, avaliação e resultados. Assim, o cursista é instigado a refletir sobre a mecânica de criar, estimular, orientar, liderar competências - mecânica esta que ancora na escola. Denominada por Saviani de "neotecnicismo", essa mecânica "surge como algo novo, entretanto, trata-se da velha maneira de perpetuar o capital humano" (2008, p. 383), pois faz com que a função da educação contribua para o aumento da produtividade e do regime de acumulação.

Outro tópico contemplado no curso de formação é a noção de "gestão participativa”. Partindo da ideia de uma democracia plena, cabe ao gestor escolar, segundo Luck e colaboradores (2010), promover uma gestão participativa que permita a atuação de todas as pessoas envolvidas com a escola, desde a equipe pedagógica até a própria comunidade em que está localizada. Segundo os autores, 
[...] a intenção é melhorar a qualidade pedagógica do processo educacional das escolas, garantir ao currículo escolar maior sentido de realidade e atualidade, aumentar o profissionalismo dos professores, combater o isolamento físico, administrativo e profissional dos gestores e professores, motivar o apoio das comunidades escolar e local às escolas, desenvolver objetivos comuns na comunidade escolar (LUCK et al., 2010, p. 18).

Cumpre ressaltar, porém, que essa proposta de gestão, mesmo alinhada a um dos pilares do programa Compromisso de São Paulo, expressa a desoneração do Estado e a transferência da responsabilidade pela educação para a sociedade civil. A nosso ver, Luck e colaboradores (2010) não se atêm ao violento movimento que o capital impõe às democracias periféricas como o Brasil, instituindo determinações que acabam por refletir-se nos atributos do diretor escolar. Assim, o gestor escolar é levado a aceitar o que lhe é imposto e incorporar conceitos de lideranças alienantes em detrimento do próprio conhecimento que deve ser estimulado na escola.

A temática central do curso, que é a "observação da sala de aula", conduzirá a uma prática rotineira da escola pelos gestores: observar aula do professor, promover um feedback e, finalmente, estabelecer um consenso para um novo planejamento das aulas, caso haja necessidade.

A realidade contraditória, como sua própria natureza, choca-se com o irreal produzido pelo curso, cujas sugestões não contemplam as diversidades e adversidades com as quais o gestor escolar precisa lidar no exercício de seu trabalho. Afinal, na escola também não existe neutralidade, pois há projetos antagônicos em disputa. O conflito irá permanecer dentro da escola, pois os anseios, mais uma vez, não serão sanados, como sugere Sampaio Jr.:

A democracia real, tal como ela existe no Brasil, não abre espaço para a transformação social. Ela funciona como mero ritual eleitoral que operacionaliza a alternância no poder entre as diferentes facções da burguesia, dando um verniz de legitimidade a um padrão de dominação que é, na sua essência, profunda e intrinsecamente antidemocrático. Para sair do impasse em que se encontra, o movimento social terá de radicalizar a crítica ao capitalismo e redefinir o modo de conceber a complexa dialética entre reforma e revolução (SAMPAIO JR., 2017, p. 73).

Em nossas reflexões acerca dos atributos do diretor de escola, cumpre considerar o papel que atualmente atribui-se ao próprio ambiente escolar, tendo em vista que, de acordo com os princípios de "aprender constantemente" e de "desenvolver competências cognitivas", o indivíduo pode ser inserido socialmente, porém depende dele se a sua formação contribuirá para um homem "em si” ou "para si”. Esse processo ocorre, segundo Duarte, quando a formação do indivíduo 
ocorre no âmbito "em si", através de um "processo de desenvolvimento que se inicia pela síntese espontânea das relações sociais, rumo a uma síntese consciente das relações sociais à individualidade para si” (2017, p. 9).

Nesse sentido, de acordo com Saviani, o diretor escolar, na sociedade capitalista, está fadado a desempenhar uma função gerencial, mesmo que seja também um educador, pois efetua "a mediação entre os dois focos de pressão: superior (o sistema) com o interior da escola (comunidade)" (2008, p. 249).

No MGME, a formação configura-se necessária para responder aos acontecimentos políticos que marcam as concepções educacionais hegemônicas reconfiguradas. Assim, cumpre mencionar as observações de Hernández, que atenta para o fato de que

Para os construtivistas, a formação dos professores de modo construtivista é fundamental para o seu sucesso nas escolas. É então desfechado um ataque maciço à formação fornecida pela universidade, que se caracterizava por uma abordagem empirista, a qual levaria à tentativa de encher a cabeça dos futuros professores com uma série de conteúdos que de nada servirão para sua prática. (HERNÁNDEZ, 1997, p. 202-206).

Para compreender o processo de formação subjacente ao curso MGME, é preciso analisar as respostas dadas à questão "o que o gestor deveria observar em sala de aula? tendo em vista que elas fornecem muitas sugestões aos educadores em formação. A resposta padrão sugere que "é papel do gestor apontar e desvelar as divergências e convergências do que se pretende com as diretrizes da escola, tendo como base o Currículo do Estado de São Paulo" (SÃO PAULO, 2016b).

O curso também estabelece que é preciso existir uma comunicação entre sala de aula, escola e SEE/SP, de modo que elas componham uma tríade unificada, tendo em vista a importância de se alinhar à estrutura para que haja avanços na educação.

Percebe-se a existência de um modelo reconfigurado do trabalho do diretor, que foi historicamente reduzido à competência técnica. O Estado, portanto, recria um sistema de controle sobre seus educadores e utiliza, para tanto, o diretor como figura necessária, que segue sem dar sustentação ao trabalho educativo - pois suas preocupações estão voltadas para a competência técnica e sem manter comprometimento político com a real e efetiva emancipação dos trabalhadores da educação.

Assim, podemos observar que, de acordo com o curso ministrado pela EFAP - e, consequentemente, de acordo com a própria SEE/SP, já que ela o promove -, o importante é que o gestor organize a maneira de observar a aula do professor. Para tanto, deve analisar o conteúdo desenvolvido na aula, levantar quais as expectativas desenvolvidas de aprendizagem, os seus aspectos organizativos, as 
condições didáticas apresentadas a favor da aprendizagem, os recursos utilizados, as relações que se estabelecem e as regularidades no comportamento e nas atitudes dos alunos e dos docentes.

Para otimizar o trabalho de observação do gestor, sugere-se que ele se prepare para realizar a observação da aula, no intuito de "aprimorá-la", tendo em vista que a sala de aula não é um espaço neutro; assim, é necessário planejar como se irá abordar esse espaço ou interferir nele, ainda que como mero observador.

Pressupondo que a ação do gestor é regida pela ideia de que os objetivos devem ser combinados a partir do mesmo foco, o curso também fornece subsídios para analisar qual é o momento correto de realizar a observação. Para o MGME, esse momento de observação de sala de aula, como parte do processo de formação do diretor, é um momento crucial. No que se refere à observação da aula propriamente dita, sugere-se aos gestores que é preciso ter "foco da observação da aula e anotar os diferentes aspectos definidos como pontos de observação" (SÃO PAULO, 2016b, p. 6).

É notável, no curso em questão, a existência de um mecanismo estabelecido de cima para baixo com o intuito de tornar constante a prática da observação da sala de aula. Nesse sentido, cumpre considerar que as escolas de tempo integral do estado de São Paulo já utilizam esse documento orientador como forma de avaliação da gestão de sala de aula dos educadores.

Conforme os módulos do MGME avançam, notamos as alusões a e relações existentes entre decretos, leis, resoluções e materiais como o Caderno do Gestor, o Caderno do Professor, a Proposta Curricular, além dos referenciais bibliográficos que influenciam as concepções pedagógicas hegemônicas. O Caderno do Gestor se materializa na relação com os pressupostos teóricos e políticos do "São Paulo Faz Escola" e, distribuído aos gestores escolares, regulamenta na prática o papel gerencial do diretor.

Percebe-se, assim, que a proposta de formação do diretor subjacente a esse curso não se configura de maneira a refletir os problemas da educação e buscar soluções para eles, mas caminha para uma formação contínua unilateral e alienante.

Dando sequência às reflexões sobre gestão, o curso sugere que, após compor o próprio perfil, cabe ao diretor implantar as ações ou práticas estabelecidas no intuito de permitir que a escola cumpra seu papel com excelência. Que práticas são estas? "Ao gestor cabe ser líder capaz de estimular e orientar a implementação do currículo nas escolas públicas estaduais de São Paulo” (SÃO PAULO, 2010, p. $10)$. 
As atribuições do diretor elencadas ao longo do curso permitem-nos afirmar que a formação do diretor escolar prevista pela SEE/SP, segundo esses moldes, limita-se sistematicamente à racionalidade econômica, à gestão de pessoas e à busca de resultados, enquanto elimina os anseios do devir histórico de trabalho educativo da função.

Assim, ao nosso ver, a análise dos pressupostos teóricos e políticos do curso MGME permite-nos afirmar que o objetivo central do curso é qualificar os gestores escolares para as especificidades "gerenciais", de modo a incorporar políticas hegemônicas e consolidar reformas educacionais.

\section{CONSIDERAÇÕES FINAIS}

"Melhor Gestão, Melhor Ensino" foi o primeiro curso para diretores fornecido via EaD pela Secretaria de Educação do Estado de São Paulo, no período entre 2013 e 2017. Ao analisar seus pressupostos políticos e teóricos, no intuito de tecer considerações acerca do processo de formação do diretor de escola proposto pela SEE/SP, foi possível perceber que estamos diante do perfil de um diretor "subjetivo", já que a especificidade do "currículo da escola se baseia no saber elaborado (ciência)" (SAVIANI, 2015, p. 288), e uma vez que o conteúdo do curso está prioritariamente voltado para questões como gestão de pessoas e busca de resultados, relegando-se a segundo plano o aspecto educativo das atribuições de um diretor escolar.

A história da educação brasileira, em sua dinâmica, é concreta, já que, mesmo que surjam perspectivas por coerências subjetivistas, é no concreto que as respostas surgem. Além disso, é na produção do Ser Humano que observamos o real e lá está, também, a formação. Nesse sentido, importa notar que a prática gestora ocorre na presença de contradições sociais, políticas, econômicas e culturais, contribuindo para que haja uma reconfiguração da paralisia da crítica, negando a perspectiva histórica, filosófica e científica dentro da escola e nos cursos de formação.

No Curso MGME ocorre a concretização gerencialista do trabalho do diretor escolar. Notamos a reconfiguração da profissão, dizimando seu trabalho educativo, em contradição com o ideal de formação que emancipa o Ser Humano omnilateral. Para Gramsci (2006 p. 39), a escola deve formar o homem para sua emancipação, adquirindo assim "uma consciência moral e social sólida e homogênea", e a posterior seguir a profissões diversas, técnicas ou não. Assim o Ser Humano omnilateral se aproxima da "objetivação como ser histórico (DUARTE, 2013, p. 135). 
Já o "aprender a aprender" promove uma formação que generaliza a escola conduzindo os indivíduos a uma "concepção educacional voltada para a formação da capacidade adaptativa dos mesmos". (DUARTE, 2013, p. 49). Processo pelo qual o indivíduo passará a ser "guiado" dentro da generecidade "em si”, ou seja, se adaptando aos costumes que lhe são propostos, através do agir espontâneo.

Notemos que a formação do indivíduo "para si”, segundo Duarte (2017, p 16.), "é a formação do indivíduo como uma pessoa que faz de sua vida uma relação consciente com o gênero humano", portanto, acreditamos que o indivíduo necessita de uma concepção educacional "para si”, que resultará em uma formação não espontânea e sim, que se aproprie das objetivações, dos conceitos filosóficos históricos e científicos, não presentes no curso de formação MGME.

Afinal, o trabalho educativo do diretor está relacionado à problematização das questões e ao encaminhamento de soluções da resolução dos problemas sociais da prática social. Nesse processo, o ponto de chegada é a prática social "em si", a qual está exclusa dos cursos de formação e precisa ir ao encontro do "para si". Como observa Saviani, o trabalho educativo do diretor deveria configurar-se como mediação da relação professor e aluno, permitindo a passagem dos educandos e professores "de uma inserção acrítica e intencional para uma situação crítica e intencional" (2012, p. 111).

O enfrentamento dos problemas relacionados às práticas sociais requer uma formação que desperte o diretor real com qual ação intencional?

Ao analisarmos o objeto curso de formação MGME, notamos a presença de uma ação "doxa", ou seja, intencional espontânea, "que significa opinião, isto é, o saber próprio do senso comum” (SAVIANI, 2015, p. 288), Para tanto, é preciso que haja uma ação intencional da SEE/SP com formação através de conhecimentos metódicos e sistematizados através da "Episteme", que significa Ciência.

Ao refletir sobre a relação entre teoria e prática, Saviani observa que "a prática é a razão de ser da teoria, o que significa que a teoria só se constitui e se desenvolveu em função da prática que opera" (2012, p. 108). Nesse sentido, cabe ao diretor empírico distanciar-se do diretor conceitual em busca de uma teoria consistente e eficaz que promova a resolução dos problemas.

Quando analisamos a ideia de que o gestor deve observar o professor em sala de aula, conforme as sugestões do MGME, é preciso alertar para o fato de que o problema da educação brasileira não é o professor, mas sim o distanciamento dos educadores em relação à prática social global. Por isso, incomoda-nos a ideia de que o curso de formação em questão não oferece a ideia de educação como 
mediadora na prática social global, como sugere a PHC, limitando-se a sugerir que o diretor faça o apontamento de sucessos e fracassos, posicionado o educador como o grande vilão de um sistema que está distante do sentido emancipador.

Para superarmos essa condição, é fundamental que o diretor empírico passe a ter uma visão sintética, articulada e também concreta, à margem de uma visão confusa e caótica do que é estabelecido nos cursos de formação. Afinal, "a prática humana é determinada pela teoria" (SAVIANI, 2012, p. 109).

A nosso ver, o perfil de diretor proposto pelo MGME está atrelado a uma formação abstrata do trabalho educativo, pois o curso pressupõe um profissional que culpa o professor e a si mesmo pelos altos índices de reprovação, atendose às considerações que resultaram das observações das aulas dos professores. Cumpre destacar, porém, que a culpabilidade do fracasso escolar não deve recair sobre o educador e, sim, sobre a própria estrutura, que não acorda com o devir histórico de formação como prática social mediadora, sugerida por Saviani, em busca de compreender o ser em si e na sua concretude. Do ponto de vista filosófico-científico a perspectiva do MGME se apresenta como uma concepção idealista, pois ela não movimenta a realidade concreta, antes parte exclusivamente da capacidade do gestor para transformar a realidade. O conflito persistirá, pois há a luta de classes no "chão da escola". Nesse contexto, o gestor desempenha um papel de maior amplitude, pois, conforme observa Saviani,

o diretor se vê concretamente diante de focos de pressão do "sistema" que privilegia a forma sobre o conteúdo impondo um conjunto de exigências burocrático-administrativas; de outro lado, (de baixo e de dentro), a pressão do conteúdo educativo que necessita ser desenvolvido no interior da escola sem o que ela se descaracteriza [...]. Em termos ideais, caberia ao diretor efetuar a mediação entre os dois focos de pressão. (1996, p. 208).

Assim, concluímos que, para que se estabeleça a concretude do trabalho educativo, é necessário que o diretor escolar entenda, na prática, que sua competência técnica deve estar atrelada a seu compromisso político e à intencionalidade das objetivações de sua individualidade, como trabalho educativo "para si". 


\section{REFERÊNCIAS}

DAMIS, Olga Teixeira. Arquitetura da aula um espaço de relações. In: ENCONTRO NACIONAL DE DIDÁTICA E PRÁTICA DE ENSINO: CONVERGÊNCIAS E TENSÕES NO CAMPO DA FORMAÇÃO E DO TRABALHO DOCENTE: POLÍTICAS E PRÁTICAS EDUCACIONAIS, 15. 2010, Belo Horizonte. DALBEN, Ângela Imaculada. Loureiro de Freitas; PEREIRA, Julio Emilio Diniz; SANTOS, Lucíola L. (Orgs.). Anais do Encontro. Belo Horizonte: Autêntica, 2010, p. 210-217.

DARDOT, Pierre; LAVAL, Christian. A Nova Razão do Mundo: ensaio sobre a sociedade neoliberal. 1. ed. São Paulo: Boitempo, 2016.

DUARTE, Newton. Vygotsky e “o aprender a aprender". Crítica às apropriações neoliberais e pós-modernas da teoria vygotskiyana. 5. ed. Campinas: Autores Associados, 2012.

A Individualidade para si: Contribuição a uma teoria histórico-crítica da formação do indivíduo. Campinas: Autores Associados, 2017.

GRAMSCI, Antônio. Os intelectuais e a organização da cultura. 4. ed. Rio de Janeiro: Civilização Brasileira, 1982.

. Os intelectuais o princípio educativo e o Jornalismo. Caderno 12. Cadernos do Cárcere. v. 2, 4. ed. Rio de Janeiro: Civilização Brasileira, 2006.

HERNÁNDEZ, P. Construindo o Construtivismo: critérios para a sua fundamentação e aplicação instrumental. In: RODRIGO, Maria José; ARNAY, José (Orgs.). Domínios do Conhecimento, Prática Educativa e Formação de Professores. São Paulo: Ática, 1997.

LUCK, Heloísa; FREITAS, Kátia Siqueira de; GIRLING, Robert; KEITH, Sherry. Escola Participativa: o trabalho do gestor escolar. 7. ed. Petrópolis: Vozes, 2010.

MANACORDA, Mario Alighiero. O princípio educativo em Gramsci: americanismo e conformismo. 2. ed. Campinas: Alínea, 2013.

. Marx e a pedagogia moderna. 3. ed. Campinas: Alínea, 2017. 
MAZZOTTI, Alda Judith Alves. "Fracasso Escolar": representações de professores e de alunos repetentes. In: REUNIÃO ANUAL DA ANPED: NOVO GOVERNO, NOVAS POLÍTICAS, 26., 2003, Poços de Caldas. Trabalhos e Pôsteres da $26^{a}$ Reunião Anual. [online]. Disponível em: <http://26reuniao. anped.org.br/tpgt20.htm>. Acesso em: 16 out. 2020.

PARO, Vitor Henrique. Gestão Democrática da Escola Pública. 4. ed. São Paulo: Cortez, 2016.

SAMPAIO JR., Plínio de Arruda. Crônica de uma crise anunciada. São Paulo: SG Amarante, 2017.

SAVIANI, Demerval. Pedagogia histórico-crítica: primeiras aproximações. São Paulo: Autores Associados, 1996.

História das Ideias Pedagógicas no Brasil. 2. ed. Campinas: Autores Associados, 2008.

Escola e Democracia. 42. ed. Campinas: Autores Associados, 2012.

Sobre a Natureza e a Especificidade da Educação. Germinal: Marxismo e Educação em Debate, Salvador, v. 7, n. 1, p. 286-293, jun. 2015.

SAVIANI, Demerval; DUARTE, Newton (Orgs). Pedagogia histórico-crítica e luta de classes na educação escolar. Campinas: Autores Associados, 2015.

SÃO PAULO (ESTADO). Centro de Referência em Educação Mario Covas. Disponível em: <http://www.escoladeformacao.sp.gov.br/portais/Default. aspx?tabid $=4031>$. Acesso em: 8 set. 2018.

Diário Oficial do Estado de São Paulo (DOE-SP). Disponível em: <imprensa oficial.com.br>. Acesso em: 4 de outubro de 2019.

Escola de Formação e Aperfeiçoamento dos Professores Paulo Renato Costa Souza. Disponível em: <www.escoladeformacao.sp.gov.br>. Acesso em: 7 jun. 2018.

Rede do Saber. Disponível em: <www.rededosaber.sp.gov.br>. Acesso em: 7 jun. 2018. 
. Regulamento SEE. Melhor Gestão, Melhor Ensino. Disponível em: <www.escoladeformacao.sp.gov.br/portais/Portals/131/regulamento_melhor_ gestao_ensino_Curso2_formacao_2017_1ed.pdf>. Acesso em: 1 dez. 2017.

. Decreto n. 651, de 6 de agosto de 1897. Disponível em: <https:// www.al.sp.gov.br/repositorio/legislacao/decreto/1899/decreto-651-29.03.1899. html>. Acesso em: 12 mai. 2019.

Decreto n. 5.431, de 5 de março de 1932. Publicado no Diário Oficial do Estado de 6/03/1932. Disponível em: <https://www.al.sp.gov.br/ norma/?id=131663>. Acesso em: 9 abr. 2018.

. Decreto n. 5.846, de 21 de fevereiro de 1933. Publicado no Diário Oficial do Estado de 22/02/1933. Disponível em: <https://www.al.sp.gov.br/ repositorio/legislacao/decreto/1933/decreto-5846-21.02.1933.html>. Acesso em: 9 mai. 2018.

Decreto n. 11.285, de 16 de março de 1978. Publicado no Diário Oficial do Estado de 17/03/1978. Disponível em: <https://www.al.sp.gov.br/ repositorio/legislacao/decreto/1978/decreto-11285-16.03.1978.html>. Acesso em: 12 ago. 2018.

. Lei Complementar n. 444 de 27 de dezembro de 1985. Disponível em: <https://www.al.sp.gov.br/repositorio/legislacao/lei.complementar/1985/ lei.complementar-44427.12.1985.html>. Acesso em: 19 mar. 2018.

. Lei Complementar n. 725, de 16 de julho de 1993. Disponível em: <www.al.sp.gov.br/norma/15561>. Acesso em: 12 ago. 2018.

. Decreto n. 40.673 de 16 de fevereiro de 1996. Institui o Programa de Ação de Parceria Educacional Estado-Município para atendimento ao ensino fundamental. São Paulo, 1996a.

. Secretaria de Estado da Educação. Resolução SE n. 27, de 29 de março de 1996. Dispõe sobre o Sistema de Avaliação de Rendimento Escolar do Estado de São Paulo. São Paulo, 1996b. 
Deliberação CEE n. 9 de 30 de julho de 1997. Institui, no sistema de ensino do Estado de São Paulo, o regime de progressão continuada no ensino fundamental. São Paulo, 1997a.

Resolução SEE de 4 de agosto de 1997. Homologa a Deliberação CEE n. 9 de 1997. Publicada no DOE, pp. 12-13. São Paulo, 1997 b.

Lei Complementar n. 836, de 30 de dezembro de 1997. Institui Plano de Carreira, Vencimentos e Salários para os integrantes do Quadro do Magistério da Secretaria da Educação e dá outras providências correlatas. São Paulo, 1997c.

Decreto n. 43.409, de 26 de agosto de 1998, alterado pelo Decreto número 57.670 de 22 de dezembro de 2011. Disponível em: < https://www.al.sp. gov.br/repositorio/legislacao/decreto/1998/decreto-4340926.08.1998.html>. Acesso em 19 mar. 2018.

. Caderno do Programa de Qualidade da Escola. São Paulo: SEE, $2007 a$.

Lei Complementar n. 1018, de 15 de outubro de 2007. São Paulo, 2007b. Disponível em: <https://www.al.sp.gov.br/repositorio/legislacao/lei. complementar/2007/lei.complem entar1018-15.10.2007.pdf>. Acesso em: 20 mar. 2018.

Decreto n. 52.630, de 16 de janeiro de 2008. São Paulo, 2008a. Disponível em: <https://www.al.sp.gov.br/repositorio/legislacao/ decreto/2008/decreto-5263016.01.2008.html>. Acesso em: 20 mar. 2018.

Resolução SE n. 27, de 11 de março de 2008. São Paulo, 2008b. Disponível em: http://deadamantina.edunet.sp.gov.br/legislacao/Res_ SE_27_2008.htm. Acesso em: 20 mar. 2018.

Resolução SE n. 76, de 7 de novembro de 2008. São Paulo, 2008c. Disponível em: <http://siau.edunet.sp.gov.br/ItemLise/arquivos/76_08. HTM?Time=24/03/2018\%2020:33:56> . Acesso em: 10 mar. 2018.

Lei Complementar n. 1078, de 17 de dezembro de 2008. Institui o sistema de Bonificação por Resultados - BR, no âmbito da Secretaria da Educação, e dá providências correlatas. São Paulo, 2008d. 
Matrizes de referência para a avaliação Saresp: documento básico. São Paulo: SEE, 2009a.

. Lei Complementar n. 1097 de 27 de outubro de 2009. Institui o sistema de promoção para os integrantes do quadro do magistério da Secretaria da Educação. São Paulo, 2009b.

. Currículo do Estado de São Paulo: Ciências Humanas e suas tecnologias. São Paulo: SEE, 2010.

Decreto n. 57.571, de 2 de dezembro de 2011. Institui, junto à Secretaria de Educação, o Programa Educação - Compromisso de São Paulo e das providências correlatas. São Paulo, 2011.

. Resolução SE- n. 22, de 18 de abril de 2013. Diário Oficial Poder Executivo Seção I. São Paulo: SEE, 2013a.

. Resolução n. 52, de 14 de agosto de 2013. São Paulo, 2013b. Disponível em: <http://www.educacao.sp.gov.br/cgrh/wpcontent/uploads/2014/06/ RESOLU $\%$ C 3\%87\%C3\%83O-SE-52-de-14-8-2013PERFIS-PARACONCURSO.pdf>. Acesso em: 20 mar. 2018.

. Lei Complementar n. 1.256, de 6 de janeiro de 2015. Dispõe sobre Estágio Probatório e institui Avaliação Periódica de Desempenho Individual para os ocupantes do cargo de Diretor de Escola e Gratificação de Gestão Educacional para os integrantes das classes de suporte pedagógico do Quadro do Magistério da Secretaria da Educação e dá providências correlatas. Disponível em: <http://www.al.sp.gov.br/repositorio/legislacao/lei.complementar/2015/ lei.complementar1256-06.01.2015.html>. Acesso em: 26 nov. 2018.

. Resolução n. 56 de 14 de outubro de 2016. Dispõe sobre perfil, competências e habilidades requeridos dos Diretores de Escola da rede estadual de ensino, e sobre referenciais bibliográficos e legislação, que fundamentam e orientam a organização de concursos públicos e processos seletivos, avaliativos e formativos, e dá providências correlatas. São Paulo, 2016a. 
Regulamento Curso: Melhor Gestão, Melhor Ensino. Disponível em: http://www.escoladeformacao.sp.gov.br/portais/Portals/131/regulamento_ melhor_gestao_ensino_Curso3_gestao_2017_1ed.pdf. Acesso em: 14 nov. 2016.

Documento Orientador: Observação de Sala de Aula da Coordenadoria de Gestão da Educação Básica (CGEB). São Paulo, SEE, 2016b. Disponível em: <https://midiasstoragesec.blob.core.windows.net/001/2017/08/17-082017 documentoorientador-protocolo-de-observao-em-sala-de-aula-2.pdf $>$. Acesso em: 19 mar. 2018.

\section{Luis Fernando Ferreira Pinto}

Mestre em Educação pela Faculdade de Educação da Unicamp. Especialista em Educação e Inserção Social pelo Instituto Federal de Campinas. Graduação em História pela PUC-Campinas e Pedagogia. Tem experiência como Professor de História e Gestor Escolar na Rede Pública Estadual Paulista e Particular. E-mail: luisf.hu@hotmail.com

\section{Regis Henrique dos Reis Silva}

Doutor em Filosofia e História da Educação pela Universidade Estadual de Campinas (2013). Atualmente é professor do Departamento de Filosofia e História da Educação da Faculdade de Educação da Universidade Estadual de Campinas (DEFHE/FE/Unicamp) e Coordenador Associado do Curso de Pedagogia da FE/Unicamp. E-mail: regishsilva@gmail.com 